\title{
Closure of a colon perforation with an autologous
} fat plug

A 60-year-old woman was referred for ileo-colonoscopy because of suspected Crohn's disease in the terminal ileum. During biopsy in the cecum, a perforation occurred at the biopsy site.

We inserted the biopsy forceps through the opening of the perforation, and managed to collect some fatty tissue from the peritoneal cavity, most probably from the nearby mesenteric fat, and pulled it back through the perforation to plug it ( Fig. 1). This fatty plug prevented acute leakage of bowel content, and gave us time to clean the colon further. An endoscopic clip was placed on the fatty plug to prevent dislocation ( $\mathbf{F i g . 2}$ ). We could then continue our examination. After the examination, the patient received prophylactic antibiotics. She did not have any symptoms during or after the procedure.

The importance of this case is the possibility to use autologous tissue to seal a gastrointestinal perforation. The fatty plug also makes it easier to perform endoscopic clipping.
Endoscopy_UCTN_Code_TTT_1AQ_2AJ

Competing interests: None

\section{Khanh Do-Cong Pham}

Department of Medicine, Haukeland University Hospital, Bergen, Norway

Bibliography

DOI http://dx.doi.org/

10.1055/s-0034-1377770

Endoscopy 2015; 47: E111

(c) Georg Thieme Verlag KC

Stuttgart · New York

ISSN 0013-726X

Corresponding author

\section{Khanh Do-Cong Pham, MD}

Section of Gastroenterology

Department of Medicine

Haukeland University Hospital

Jonas Lies vei 65

5051 Bergen

Norway

Fax: +47-5-3414078

phamkdc@gmail.com

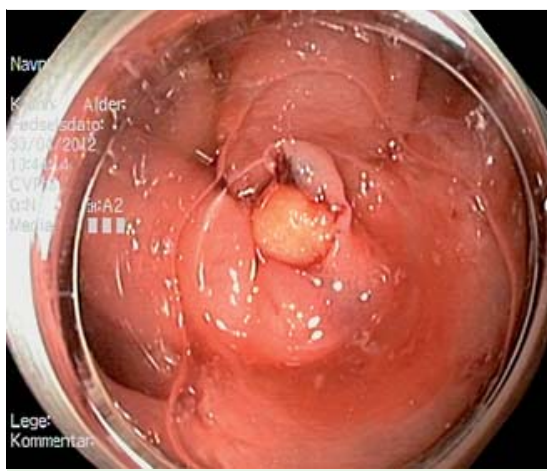

Fig. 1 Fatty tissue from the peritoneal cavity was used to plug a perforation which occurred during a biopsy in the cecum in a 60-year-old woman.

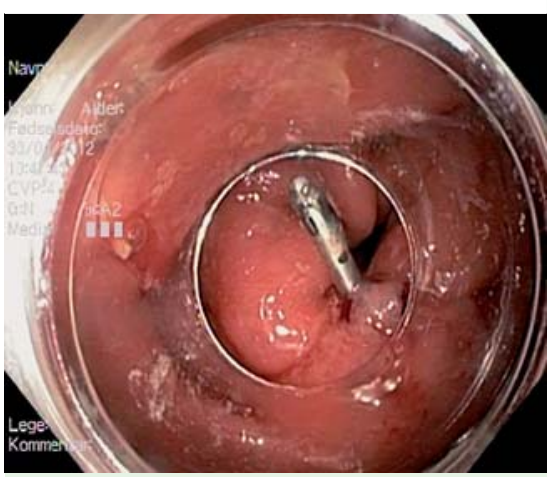

Fig. 2 Clipping of the perforation with the fatty plug to prevent dislocation. 